\title{
(Des) Liga esse celular, moleque! Smartphone como minilaboratório no ensino de Ciências
}

\author{
(off) League this phone, kid! \\ Smartphone as mini-lab in science teaching
}

\author{
Márcio Delmondes da Rocha1, Edson Gomes Evangelista², Nadja Gomes Machado³, Geison Jader \\ Mello 4
}

\author{
${ }^{1}$ Licenciado em Ciências da Natureza, Campus São Vicente, Instituto Federal de Mato Grosso, Jaciara, MT, Brasil \\ ${ }^{2}$ Doutorando em Educação, Núcleo de Jaciara, Campus São Vicente, Instituto Federal de Mato Grosso, Cuiabá, MT, Brasil \\ ${ }^{3}$ Doutora em Física Ambiental, Laboratório de Biologia da Conservação, Campus Bela Vista, Instituto Federal de Mato \\ Grosso, Cuiabá, MT, Brasil
}

${ }^{4}$ Doutor em Física Ambiental, Núcleo de Jaciara, Campus São Vicente, Instituto Federal de Mato Grosso, Jaciara, MT, Brasil

\begin{abstract}
Resumo
A literatura científica tem apresentado significativo número de publicações sobre a utilização de recursos tecnológicos como tablets e smartphones no ensino de ciências. São bastantes positivos os relatos de experiências que buscam tornar o ensino de ciências mais atrativo, desenvolvendo métodos diferenciados, praticados pela maioria dos educadores, tornando o processo de ensino aprendizagem mais dinâmico. Além das diversas experiências relatadas, as organizações, como a UNESCO, têm incentivado ações nessa perspectiva e têm divulgado documentos ostentativos. No entanto muitas escolas ainda compreendem essas tecnologias como um adversário, subestimando-as, desconsiderando seu grande potencial em serem utilizadas como ferramenta pedagógica. É possível fazer destes dispositivos um minilaboratório de experimentos científicos, que além de potencializar a aprendizagem significativa, transforma a experiência em um mecanismo que leva a reflexão do construído, integra o ensino de Ciências ao cotidiano dos estudantes, interagindo a aprendizagem com a realidade dos alunos. As tecnologias das comunicações móveis, smartphone e seus derivados, fazem parte da identidade cultural dos estudantes e possibilitam aos alunos desenvolver suas próprias experiências científicas de maneira autônoma, levando o conhecimento construído em sala de aula ao exterior do meio escolar, permitindo a disseminação de seu aprendizado, bem como a divulgação de suas experiências nas redes sociais, tornando possível ao aluno aprender e ensinar ao mesmo tempo. O objetivo deste trabalho é ensinar conteúdos de ciências utilizando como ferramenta o smatphone/tablet como laboratório didático de forma a obter aprendizagens significativas.

Palavras chave: Ferramenta pedagógica. Aprendizagem significativa. Tecnologias das comunicações móveis
\end{abstract}

\begin{abstract}
The scientific literature has shown significant number of publications on the use of technological features such as tablets and smartphones in science education. Are enough positive reports of experiences that seek to make teaching more attractive sciences, developing different methods, practiced by most educators, making the dynamic process of teaching and learning. In addition to the many reported experiences, organizations such as UNESCO, have encouraged action in this perspective and have released ostentativos documents. However many schools still include these technologies as an opponent, underestimating them, disregarding their great potential to be used as a pedagogical tool. You can make these devices one mini-lab of scientific experiments, which besides enhancing meaningful learning, transforms the experience into a mechanism that leads to reflection built, integrates the teaching of science to the daily lives of students, learning by interacting with the reality of students. The technologies of mobile communications, smartphone and its derivatives, are part of the cultural identity of students and enable students to develop their own scientific experiments autonomously, bringing knowledge built in the classroom to the outside of the school environment, allowing the dissemination of its learning and the dissemination of their experiences on social networks, enabling the student to learn and teach at the same time. The objective of this work is to teach science content using as a tool the smatphone / tablet as a teaching laboratory in order to obtain meaningful learning.

Keywords: Pedagogical tool. Meaningful learning. Mobile communications technologies
\end{abstract}




\section{Introdução}

Aparelhos como tablets, smartphones e seus derivados se fazem cada vez mais presentes na sociedade contemporânea. Em um toque, as informações são acessadas em velocidades cada vez maiores, os aplicativos facilitam a vida das pessoas de tal forma que essas tecnologias estão adentrando os portões das instituições de ensino, sejam-nas da educação básica ou da superior.

Atualmente, a tecnologia a serviço da educação existe e está disponível, porque foi produzida. No entanto, essa tecnologia nem sempre está acessível, sobretudo para professores e estudantes de escolas públicas. Mesmo com a enorme quantidade de aparatos tecnológicos existentes, aos professores restam o uso do giz, quadro e livro didático que ainda são os mais utilizados. A juventude atual faz parte de um mundo com tecnologia disponível e facilmente acessível, que não permite barreiras entre o espaço e tempo. Um mundo multicultural acessado com apenas um toque na tela de um aparelho de telefonia móvel, onde estes permanecem conectados nas redes sociais diariamente em tempo integral, fato que configura uma nova tendência das comunicações.

A escola parece não estar acompanhando o desenvolvimento social, ela se excluiu do meio vivido por seu público alvo, ficando defasada e desatualizada em relação às tecnologias popularizadas e utilizadas pela própria comunidade. Mas especificamente os smartphone, aparelhos com tanto potencial a ser explorado, não seria uma boa ferramenta auxiliadora na aprendizagem significativa?

Este tema é complexo, pois, no decorrer da pesquisa, pude observar divergências entre algumas escolas do vale do São Lourenço, o qual é composto de cinco municípios Matogrossenses, sendo estes: Campo Verde, Dom Aquino, Jaciara, Juscimeira e São Pedro da Cipa, no tocante ao uso do celular no interior da escola. Algumas proíbem, podendo ocorrer o risco de sanções punitivas, outras tem acesso restrito, os alunos levam os aparelhos e os guardam em uma caixa, sendo seu uso proibido no interior da instituição de ensino. Há também escolas que exercem total liberdade ao uso do celular, porém não incentivam e nem realizam qualquer uso pedagógico dos aparelhos de telefonia móvel e outras utilizam os dispositivos como ferramenta pedagógica.

Problematiza-se também que, nesta comunidade do vale do são Lourenço, mais precisamente nos municípios de Jaciara, Juscimeira e São Pedro da Cipa, as escolas não chegaram num consenso sobre o uso das tecnologias móveis, Smartphones e derivados, como ferramentas auxiliadoras das práticas docentes e demonstram ainda que falta uma política de estratégias objetivando inserir tais tecnologias, as quais fazem parte da cultura dos estudantes no processo de ensino-aprendizagem, potencializando no aluno a aprendizagem significativa, que é um processo por meio do qual uma nova informação interage, interligando o conhecimento já existente no individuo de forma substantiva, não-literal e não-arbitrária, a um aspecto relevante, dando sentido à estrutura do conhecimento do indivíduo.

Pensando em tornar o ensino mais atrativo, a escola tem que se libertar do resquício tradicionalistas/tecnicistas e se renovar, adaptando-se as práticas pedagógicas, inserindo-as no cotidiano dos estudantes. Seguindo este raciocínio, propusemos então a utilização do smartphone e seus derivados como ferramentas pedagógicas na aprendizagem significativa voltada ao ensino de Ciências.

Desta forma, objetivou-se, com este trabalho, aplicar o uso das tecnologias no ensino de ciências, física e cinemática, usando smatphone/tablet como ferramenta pedagógica com base na teoria da aprendizagem significativa.

Historicamente grandes estudiosos revolucionaram o mundo, divulgando suas descobertas científicas contribuindo com a evolução da sociedade contemporânea, como a exemplo de Albert Einstein que mudou as bases da física, com a teoria da relatividade, alterando conceitos tão fundamentais como o tempo e espaço, (MOURÃO 2005). Outro importante nome que marcou na história mundial é o médico e pesquisador brasileiro Carlos Chagas que salvou milhares de vidas ao descobrir a doença que levaria seu nome, o mal de Chagas que é 
provocado pelo parasita Tripanossoma Cruzi, (MARCOLIN 2014). E isso destaca a importância de se estudar Ciências em sala de aula, Alves (1981) nos diz que, a Ciência desempenha um papel vital. Contribuindo exclusivamente como mecanismo de adequação para nossa sobrevivência, a ciência que não se relaciona com vida perde a sua identidade. $O$ ensino de ciências, não é somente tomar parte do processo de ensino aprendizagem, de forma mecânica, as ciências têm significado importante, elas sofrem e exercem influência em nosso cotidiano no contexto social, econômico e histórico, no qual estão inseridas.

Para o ensino das Ciências Naturais, os Parâmetros Curriculares Nacionais propõem conhecimentos em função de sua importância social, de seu significado para os alunos e de sua relevância científicotecnológica, organizando-os nos eixos temáticos "Vida e Ambiente", "Ser Humano e Saúde", “Tecnologia e Sociedade" e "Terra e Universo", BRASIL (PCN.1998 pag,62).

As ciências trazem grande impacto no desenvolvimento social, econômico e cultural da nação, sendo importante via de crescimento da sociedade. Brito Cruz (2014) afirma que "O impacto social envolve ideias que afetam políticas públicas. O impacto econômico é relativo às ideias que criam empresas, as que aumentam a competitividade de empresas e aquelas que criam setores industriais". E ainda relata que o grande responsável por esse impacto econômico, evidentemente são nossas universidades, pois sem a formação eficiente do nível superior no país não existiria a indústria do petróleo, a indústria aeronáutica e outras que têm feito a diferença no Brasil.

Tornou-se uma necessidade inadiável a boa utilização das ciências por governantes, técnicos e pesquisadores esclarecidos. Nunca um país necessitou tanto de Ciência quanto o Brasil, em face de sua originalidade física, ecológica, social e humana; devendo sempre ser lembrado que os estudos básicos para uma correta elaboração de qualquer projeto, dito desenvolvimentista, depende de contribuições das ciências aplicadas, (Ab’Sáber. 2009, pag,95.)

Como educadores do futuro, conectados ao presente, temos a responsabilidade de planejar aulas que possibilitem a construção do conhecimento fazendo com que os estudantes percebam e entendam o mundo ao seu redor desenvolvendo a busca pela descoberta dos fenômenos estudados, ou seja, uma aprendizagem que seja contextualizada e significativa. Para se alcançar a aprendizagem significativa Moreira enfatiza:

\footnotetext{
Para isso é preciso: Aprender/ensinar perguntas ao invés de respostas. (Princípio da interação social e do questionamento). Aprender a partir de distintos materiais educativos. (Princípio da não centralidade do livro de texto). Aprender que somos preceptores e representadores do mundo. (Princípio do aprendiz como preceptor/representador). Aprender que a linguagem está totalmente implicada em qualquer e em todas as tentativas humanas de perceber a realidade. (Princípio do conhecimento como linguagem). Aprender que o significado está nas pessoas, não nas palavras. (Princípio da consciência semântica). Aprender que o homem aprende corrigindo seus erros. (Princípio da aprendizagem pelo erro). Aprender a desaprender, a não usar conceitos e estratégias irrelevantes para a sobrevivência. (Princípio da desaprendizagem). Aprender que as perguntas são instrumentos de percepção e que definições e metáforas são instrumentos para pensar. (Princípio da incerteza do conhecimento). Aprender a partir de distintas estratégias de ensino. (Princípio da não utilização do quadro-de-giz). (Moreira, 2005, p.15-16)
}

Como ensino e aprendizagem são indissociáveis, Freire afirma que "ensinar não é tran sferir conhecimento, mas criar as possibilidades para a sua própria produção ou a sua construção," (1996. Pag.12). Para proporcionar aos educandos uma compreensão do que é a ciência de fato, enfatizando a importância do ensino de ciências demonstrando aos estudantes que o conhecimento científico interfere em nossas relações com o mundo, o BRASIL (PCN 1998), propõe que o aprendizado tem que despertar no aluno a compreensão do mundo, para isso o aluno tem que desenvolver sua capacidade de adquirir e processar informações que 
consubstanciaram suas tomadas de decisões, estimulando assim, sua capacidade critica em seu meio social.

Os estudantes participando efetivamente dos experimentos, ainda apresentam dificuldade em relacionar os conceitos apresentados em aula com as observações e medições realizadas no laboratório. Possivelmente isto seja devido ao alto grau de abstração em que os conceitos (físicos) estão imersos (SCALCO \& APPOLINÁRIO, 2011). Wisman \& Forinash (2008) propõem o uso de objetos do cotidiano, como telefones celulares, que possam ser utilizados como objetos de aprendizagem durante as aulas de laboratório de Física.

\title{
2 Smartphones e tablets como laboratório didático
}

Reforçamos que os aparelhos como tablets e smartphones e seus derivados se fazem cada vez mais presentes na sociedade contemporânea. Em um toque, as informações são acessadas em velocidades cada vez maiores, os aplicativos facilitam a vida das pessoas de tal forma que essas tecnologias estão adentrando os portões das instituições de ensino, seja elas da educação básica, seja da educação superior (BERNARDO; 2013; FONSECA, 2013; RUIZ, 2013, RITCHIE et al.; 2013).

Abordamos o assunto por meio das palavras de MORAN (2000):

\begin{abstract}
A construção do conhecimento, a partir do processamento multimídia é mais livre, menos rígida, com maior abertura, passa pelo sensorial, emocional e pelo racional; uma organização provisória que se modifica com facilidade. Convivemos com essas diferentes formas de processamento da informação e dependendo da bagagem cultural, da idade e dos objetivos, predominará o processamento seqüencial, o hipertextual ou o multimídico. (MORAN. 2000).
\end{abstract}

O desenvolvimento deste projeto visou a tornar o ensino de ciências mais atrativo, viabilizando o uso do Smrtphone e seus derivados como ferramentas pedagógicas, auxiliadores no processo de ensino- aprendizagem, tornando esses aparelhos instrumentos de experimentações no ensino de Ciências durante as aulas práticas, possibilitando ao estudante a interação com o equipamento, e uns com os outros. Assim o estudante deixa de se limitar ao estudo apenas na escola e passa a ser um divulgador de suas descobertas cientificas. "Enquanto a educação formal, historicamente, tem sido confinada às quatro paredes das salas de aula, os dispositivos móveis podem se adequar a novas aprendizagens", (UNESCO, 2013).

A proposta do projeto foi fazer uma atualização das práticas pedagógicas, fazendo com que os estudantes de ciências construam seu conhecimento utilizando para isso uma ferramenta que já faz parte do cotidiano: o smartphone e seus derivados, aparelhos esses recheados de aplicativos para desenvolver as mais variadas tarefas. Nesta perspectiva:

\footnotetext{
Os futuros professores que se formam nas licenciaturas (Física, Química e Matemática) devem ter em mente que serão professores orientadores dos alunos nativos digitais e deverão trabalhar suas aulas com conceitos e teorias, experimentos, hipermídias, softwares específicos interativos (AVA), comunicação educativa e ligação entre teoria e realidade do aluno (modelagem matemática e outras ferramentas) (BARROQUEIRO et al., 2009).
}

Sob o ponto de vista de Ausubel, (1918-2008), o professor deve provocar questionamentos. Propondo desafios, que acionem a criatividade dos estudantes na busca por respostas e formulação de novas perguntas. Uma vez que aprender é um ato que estabelece conexões de acordo com as vivências individuais, é preciso flexibilidade para compreender que nem todas as respostas são semelhantes, tampouco todas as perguntas se equivalem. 


\section{Material e Métodos}

\subsection{Descrição da Escola}

Na fase de regência, atuamos na escola Estadual São Francisco, localizada no município de Jaciara MT que é uma escola pública situada à avenida Antônio Ferreira Sobrinho, no ${ }^{1.536}$, centro, em um prédio pertencente à Congregação das irmãs Catequistas Franciscanas, que desenvolvem atividades na comunidade desde 1.959 e é mantida pela Rede Oficial de Ensino do Ensino do Estado de Mato Grosso - Secretaria de Educação/SEDUC. A escola foi criada pelo decreto no 847 de 29 de dezembro de 1976, tendo sido autorizada a funcionar em Jaciara, Estado de Mato Grosso, pela resolução oㅡ. 50 de 26 de julho de 1979, reconhecido Ensino de ensino fundamental nível I a VIII, nos termos da portaria no 3277/92- Secretaria de Educação rege-se pelo Regimento interno da Escola, e Leis que embasam a Educação no Estado e Mato Grosso e da Federação (Figura1).

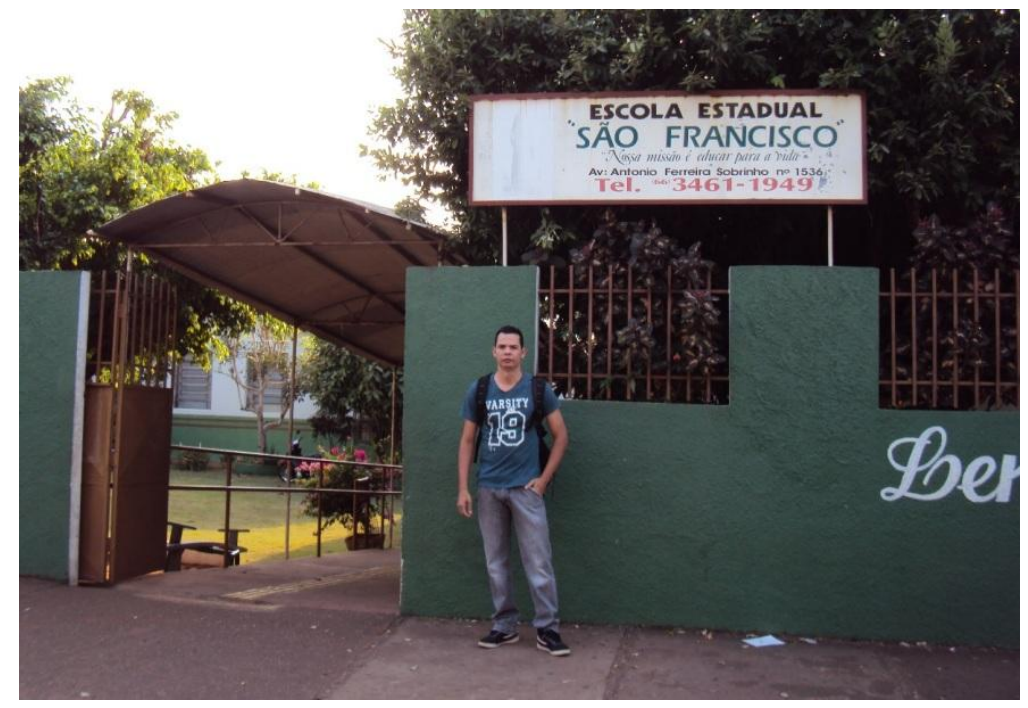

Figura 1 - Escola Estadual São Francisco.

Fonte: Cezar Silva de Oliveira

A instituição trabalha dentro do sistema do ensino da Escola Ciclada de Mato Grosso, especificamente com o ensino fundamental e educação inclusiva, visando à formação integral dos alunos, bem como da comunidade em geral, é que a escola adotou, como metodologia de trabalho a Educação libertadora, dentro do sistema de Ciclos de Formação Humana, com linhas Norteadoras para a interdisciplinaridade, implantadas pela SEDUC, cujo objetivo principal é formar cidadãos críticos, pensantes.

Atende uma clientela diversificada com cerca de 800 alunos do ensino fundamental, nos períodos matutino e vespertino, de diversas classes sociais, portadores de necessidades especiais, direcionados em duas modalidades: regular e sala multifuncional, alunos estes pertencentes a zona rural e urbana do mesmo município, municípios vizinhos e outros estados.

\subsection{Metodologia}

A metodologia utilizada neste trabalho baseou-se em uma pesquisa qualitativa, apresentando descrições dos dados coletados como caráter fundamental do estudo (MANNING, 1979). Estas pesquisas costumam ser direcionadas ao longo do desenvolvimento, não é realizada com objetivo de enumerar dados, ela tem por objetivo interpretar e decodificar os dados coletados de forma a descrever o processo da pesquisa.

O trabalho foi desenvolvido utilizando-se de três aplicativos, baixados para uso no smartphone e seus derivados sendo eles o Velocímetro, Pedômetro e o Runkeeper e os que compõem 
a configuração de fábrica dos smartphones e seus derivados: a calculadora e o cronômetro ao quais foram empregados em aulas de Ciências em duas turmas do $9^{\circ}$ ano.

A escolha dos aplicativos se deu, para aproveitar a matéria que estava sendo trabalhada nos $9^{\circ}$ anos, visando a não atrapalhar a sequência preparada pela professora titular, onde a mesma seguia o livro didático ministrando a matéria, física do calor e movimentos. Embora faça parte da norma da escola recolher os celulares dos estudantes ao entrarem no prédio escolar, por ser proibido o uso desses aparelhos de comunicação móvel, a direção escolar permitiu o uso dessa tecnologia para realização da intervenção.

O percurso metodológico constou de três fases, sendo elas: duas aulas teóricas, utilizando o livro didático, texto complementar e exercícios, uma aula para intervenção propriamente dita, utilizando os smartphones e seus derivados, e aula final retornando para sala de aula onde foram discutidos os resultados da experiência contextualizando o tempo dos alunos com o tempo do atleta velocista Usain Bolt.

Os mecanismos utilizados para a coleta de dados foram: questionário prévio, análise do resultado da intervenção, observação do comportamento dos alunos durante a realização da intervenção e produção de relatórios que foram elaborados pelos próprios alunos, constando procedimentos realizados e os resultados obtidos através destes e finalizando, pós-questionário.

Seguem elencados abaixo os passos metodológicos percorridos no desenvolvimento deste trabalho:

Passo I: da sondagem inicial. Na sondagem inicial sobre acesso as tecnologias da informação, realizou-se estudo em algumas escolas dos municípios de Jaciara, São Pedro da Cipa e Juscimeira, pertencentes a região do vale do São Lourenço em Mato Grosso. Nesta fase também se aplicou um questionário.

Passo II: da aula teórica em sala de aula. Aula expositiva e dialogada, com quadro branco, pincel, livro didático, texto complementar. Tempo: 2 horas aula.

Passo III: das aulas de intervenção. Na quadra de esportes, utilizando-se de trena para medir o comprimento da quadra e celulares, smartphones, e tablet. Bem como os aplicativos Runkeeper, Pedômetro-Aptidão, Velocímetro - Speed Gun, e Cronometro, para a coleta de dados.

Passo IV: do retorno à sala de aula. Uso de quadro e pincel, para discutir os resultados obtidos na experiência cientifica.

Passo V: da avaliação. A avaliação se dividiu em três fases sendo: participação na intervenção com o uso de smartphones e tabletes, discussão dos resultados da experiência em sala de aula utilizando o quadro branco e pincel e finalmente relatório da intervenção.

Passo VI: questionário pós intervenção. Realizou-se pós-questionário para levantar informações específica quanto ao uso dos de smartphones e tabletes como laboratório de ciências.

\section{Resultados e Discussão}

Esta pesquisa foi realizada em quatro turmas do $9^{\circ}$ ano, período matutino, da Escola Estadual São Francisco, constatou-se que dos 85 alunos que responderam o questionário, 81 possuem celulares, smartphones ou tablets, e 80 deles tem acesso à internet, entre os entrevistados apenas 3 disseram não saber utilizar o aparelho celular, 2 não responderam a questão, fato que facilitaria a experiência, no sentido de que a grande maioria conhece o funcionamento dos celulares, (Tabela1).

A partir da tabela 1 é possível observar que os celulares, smartphones e tablet's estão inseridos na cultura da maioria desses estudantes, por tanto seria viável desenvolver práticas pedagógicas que contemplasse os aparelhos de telefonia moveis como incentivo na construção do conhecimento, aproveitando o potencial que esses dispositivos dispõem, bem como estimulando o aluno a utilizar os smartphones e seus derivados, como mecanismo facilitador de aprendizagem, uma vez que o estudante tem habilidade e facilidade no manuseio destes aparelhos, além de desfrutarem de um instrumento que apreciam. 
Tabela 1. Questionário pré-intervenção.

\begin{tabular}{|c|c|c|c|}
\hline Resposta do Questionário respondido por 85 alunos & Sim & Não & Sem resp. \\
\hline 1 Sabe usar o computador mesmo que não tenha. & 84 & 01 & \\
\hline 2 Possui celular, smartphone ou tablet. & 81 & 04 & \\
\hline 3 Os aparelhos possuem internet. & 80 & 05 & \\
\hline 4 Sabe utilizar o celular mesmo que você não tenha. & 80 & 03 & 02 \\
\hline 5 Pesquisa tarefas na internet. & 65 & 20 & \\
\hline 6 Usou o celular em auxílio na resolução de atividades. & 75 & 10 & \\
\hline $7 \quad$ Gostaria de utilizar celular para ajudar nas atividades. & 77 & 08 & \\
\hline 8 Baixa aplicativos & 81 & 04 & \\
\hline 9 Já utilizou eletrônicos em aulas de ciências. & 27 & 58 & \\
\hline
\end{tabular}

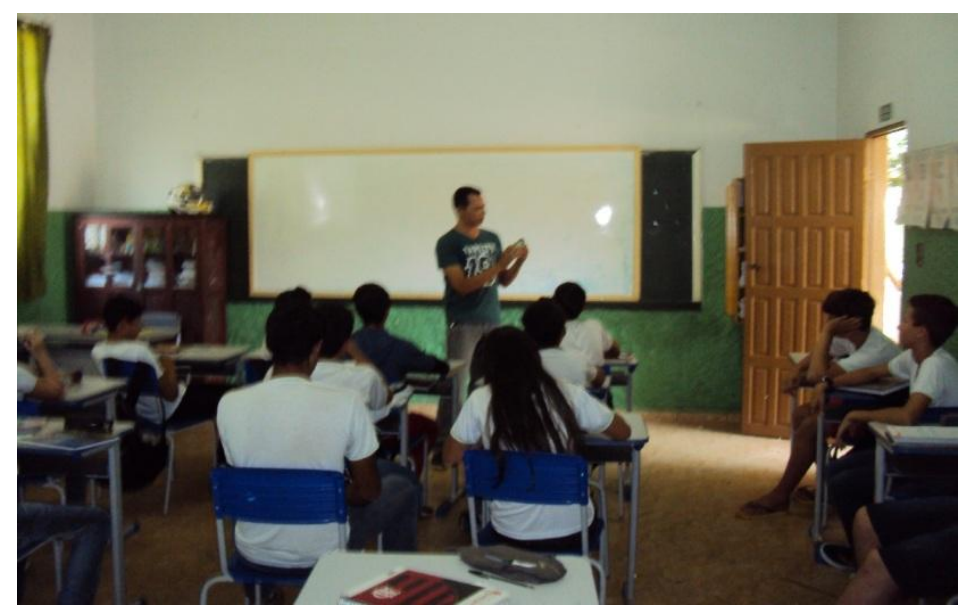

Figura 2 - Aulas teórica com os estudantes do $9^{0}$ ano da escola

Durante a aula teórica, após serem informados da proposta de realização de experiência cientifica, na qual teriam a oportunidade de usar os seus aparelhos de comunicação, móvel smartphones e seus derivados, os alunos ficaram curiosos e ansiosos, um dos fatores que contribuíram com a ansiedade desses alunos talvez tem a ver com o fato deles não poderem portar seus aparelhos no interior da escola por norma regulamentada na mesma.

O conteúdo discutido em sala de aula foi cinética, referencial, trajetória velocidade instantânea e velocidade média onde através da leitura dos textos contextualizado com vários exemplos, os estudantes foram muito participativos sempre colaborando com respostas e ao serem indagados sobre o que sabiam a respeito e o que deduziam, fizeram bastantes perguntas e às vezes discutiam entre eles sobre as possíveis respostas, realmente foi uma aula muito produtiva e significativa.

Dias antes da intervenção, constantemente os estudantes indagavam sobre o dia da realização da experiência científica e alertavam para o não esquecimento da aula, utilizando o smartphone ou derivados bem como, confirmavam que já tinham baixado os aplicativos onde realizaram os testes, 
antecipando o aprendizado do funcionamento dos mesmos, e informavam ainda o seu desempenho ao testar os aplicativos. (Figura 3a e 3b).

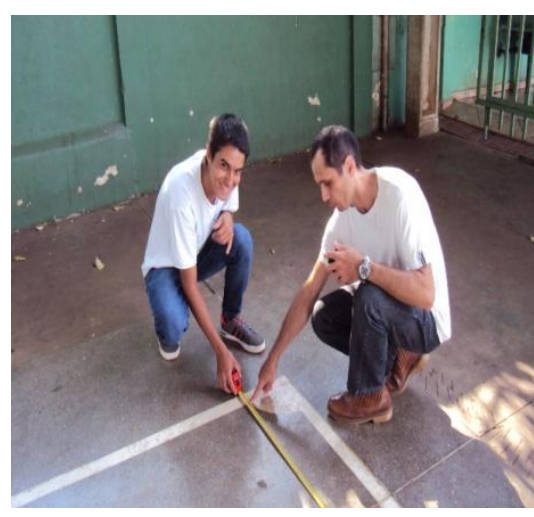

(a)

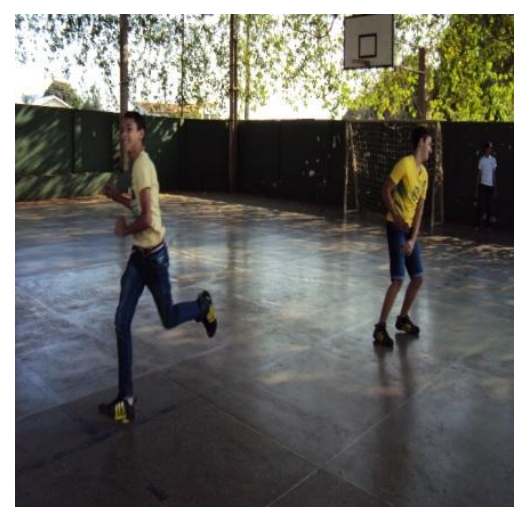

(b)

Figura 3 - Intervenções com alunos na quadra de esportes.

Sendo a proposta da aula utilizar como recurso pedagógico um aparelho celular, tecnologia essa inserida no cotidiano dos estudantes, aproveitando os conhecimentos que o aluno já possui em relação a esse aparelho para a construção de um novo conhecimento em Ciências.

Utilizou-se como recursos dos smartphones e seus derivados os aplicativos propostos para serem baixados, bem como o cronômetro e calculadora, que são recursos já existentes em qualquer celular. A experiência foi realizada na referida quadra, onde mediu-se a lateral demarcada para futsal, tendo a mesma o comprimento de $25 \mathrm{~m}$, alguns alunos de forma autônoma foram realizando a atividade conforme eles deduziam, como seria a utilização dos smartphones ou derivados, testando os aplicativos.

Posteriormente os alunos foram divididos em duplas ao passo que um dos membros da dupla, realizava o deslocamento entre as extremidades da linha lateral da quadra sendo corrida ou caminhada e coleta dos dados, utilizando um dos aplicativos propostos, sendo o runkeeper, pedômetro ou cronometro do smartphone ou derivado, enquanto outro aluno, ficou em repouso sendo um espectador da ação realizada pelo seu parceiro e ao mesmo tempo utilizava o aplicativo velocímetro do smartphones ou derivados, para também coletar dados da experiência aplicada, sendo posteriormente invertidos os papéis da ação. Ao término da experiência reuniu-se os alunos na arquibancada onde usavam as informações coletadas nas experiências científica, para realizar os cálculos conforme fórmula matemática, desvendando-se os conceitos relacionados a velocidade média percorrida por cada um, dando significado ao aprendizado construído no ensino de ciências.

Durante a realização dos cálculos apareceram, algumas dúvidas diante dos resultados expressados pelos aplicativos dos smartphones ou derivados na parte da matemática, logo os alunos observaram que os aplicativos sempre demostravam números no máximo com dois dígitos e ao compararem, perceberam que alguns resultados da divisão com os cálculos realizados nas calculadoras dos smartphones ou derivados, tiveram longas sequencias de números, então questionaram, o por quê ocorria este fato, o qual foi uma excelente oportunidade para reforçarmos os conceitos matemáticos dos números decimais, frações e dizima periódica, além de reforçar os conceitos de referencial, deslocamento, trajetória e distância percorrida, que foi a teoria aplicada em sala de aula.

Por estarem trabalhando com algo que eles já conheciam e tinham certa intimidade na utilização, possibilitou que ficassem mais seguros durante a experiência, bem como desenvolvessem suas próprias experiências, posteriormente divulgando-as em suas redes sociais. Durante este percurso os estudantes demonstraram curiosidade a ponto de alguns anteciparem a experiência ao baixarem os aplicativos propostos, conforme relatos de alguns alunos durante os dias que antecederam a intervenção. Na intervenção propriamente dita, os estudantes estavam empolgados em usar os smartphones e respectivos derivados na realização da experiência científica. Todos participaram e realizaram as atividades propostas na experiência bem como desenvolveram outras atividades 
durante o experimento.

Durante as discussões, os alunos compararam a velocidade média percorrida entre eles e a do atleta velocista Usain Bolt, cuja informação está contida no livro didático. Também foram solucionados alguns exercícios do referido livro.

O segundo questionário realizado pós-atividade, demonstrou que os alunos gostaram da novidade e surtiu até um efeito inesperado; eles comentaram a importância de praticar atividades físicas, inclusive ao demonstrar aos pais despertando-os para uma vida mais salutar.

Relacionaram ciências com matemática e educação física, afirmaram que a aula foi divertida e a maioria afirmou que as atividades os ajudaram a descobrir ciência através do aprendizadoconstruído na experiência realizada.

\section{Conclusões}

No ensino de Ciências o ato de se fazer experiências é fundamental no processo de ensino aprendizagem, pois a curiosidade motivada pelos experimentos didáticos, potencializa os alunos a fazerem descobertas sobre os fenômenos estudados, fortalecendo o princípio do ensino que faz sentido. Porém nem todas as escolas podem ofertar um laboratório de experimentos científicos, sobrecarregando no professor a responsabilidade de elaborar aulas diferenciadas capazes de suprir a falta de estrutura na escola.

Este projeto tirou proveito das características de processamento de dados e mobilidade dos Smartphones e derivados como ferramenta pedagógica auxiliadora na aprendizagem significativa, porém, apesar deste mecanismo ter um grande potencial para utilização nas práticas docentes, os smartphones e derivados ainda são pouco utilizados como meio didático nas escolas.

Constatou-se ainda, que as novas tecnologias da comunicação fazem parte da cultura e da identidade dos estudantes atuais, e, os alunos da escola São Francisco, estão em sua grande maioria, inseridos neste contexto tecnológico, o que viabilizou o uso dos smartphone e seus derivados como minilaboratório no ensino de ciências. Essa integração, entre os Smartphones e derivados com as experimentações didáticas, tiveram aplicação extremamente positiva na atividade prática.

Essa intervenção poderia ter contado com o auxílio de professores de outras áreas tornando o aprendizado mais enriquecedor, pois durante a experiência, surgiram oportunidades de contextualizar o experimento com outras disciplinas e a possibilidade de agregar esses conhecimentos tornaria a aprendizagem significativa mais ampla, uma vez que a aula prática oportunizou aos estudantes uma reflexão crítica acerca do conteúdo, fazendo com que abrangesse a curiosidade em relação ao estudado, ocorrendo algumas dúvidas foram além da aula de ciências.

Analisando a intervenção no todo, observou-se que o uso da tecnologia no ensino de ciências, agradou de forma concisa a todos os estudantes superando as expectativas destes em relação a experiência. Dentre vários relatos feitos pelos discentes, destaca-se um que resume exatamente a essência da intervenção, embasando a ideia central do tema, quando uma aluna do $9^{\circ}$ ano (A) descreve a seguinte frase "gostei muito dessa aula, pois foi diferente, usamos uma coisa que amamos que é o celular e juntamos com uma coisa que precisamos". De fato diversos relatos exaltaram a aula diferente, que proporcionou diversão enquanto construía-se o conhecimento, bem como, percebeu-se que o aprendizado construído passava a fazer sentido ao ser relacionado ao cotidiano a partir do momento em que os estudantes descobriam a utilidade do conteúdo aplicado na experiência interligando as disciplinas.

Por fim, os estudantes se dedicaram às experiências científicas, ao mesmo tempo em que se divertiam, fazendo do processo, descobertas muito mais dinâmicos e atrativos. Outro motivo agregador é o fato dos estudantes possuírem seus próprios aparelhos, proporcionou aos mesmos uma maneira de inserir a Ciência em sua realidade, e oportunizou que estes repetissem a experiência de maneira autônoma no exterior da escola, possibilitando novas descobertas e disseminando o conhecimento entre seus pares, além de divulgar o conhecimento construído em suas redes sociais. 


\section{Agradecimentos}

À Coordenação de Aperfeiçoamento de Pessoal de Nível Superior (CAPES) pelo subsídio através do Programa de Consolidação das Licenciaturas (PRODOCENCIA) Edital 019/2013, processo № 113.657, e do Programa Institucional de Bolsa de Iniciação à Docência (PIBID) Edital № 061/2013, processo № 128.570, IFMT/Campus São Vicente/Sub Projeto Ciências.

\section{Referências}

AB'SÁBER, Aziz Nacib Relevância e significado da educação científica para o Brasil.

ALVES Rubem. Filosofia da Ciência: Introdução ao jogo e suas regras, Editora Brasiliense 1981.

AUSUBEL, D. P. A aprendizagem significativa: a teoria de David Ausubel. São Paulo: Moraes, 1982.

AUSUBEL, David Paul, NOVAK, Joseph e HANESIAN, Helen. Psicologia educacional. Rio de Janeiro: Interamericana, 1980.

BARROQUEIRO, Carlos Henriques, (VII ENPEC Encontro Nacional de pesquisa em Educação em Ciências) $\mathrm{O}$ uso das Tecnologias de Informação e Comunicação no Ensino de Ciências e Matemática: uma benção ou um problema? Florianópolis-SC,08 de novembro de 2009.

BERNARDO, Julio César Oliveira, (Revista EDaPECI, Educação a Distância e Praticas Educativas Comunicacionais e Interculturais), Dispositivos Móveis Digitais na Incrementação do Processo de Ensino e Aprendizagem: Mobile Learning no Rompimento de Paradigmas, Vol. 13; N.1 Jan./abr.2013

BRASIL, Ministério da Ciência, Tecnologia e Inovação (MCTI), Edição e organização/Secretaria Executiva do Ministério da Ciência, Tecnologia e Inovação, Projeto Gráfico/Centro de Gestão e Estudos Estratégicos (CGEE), Diagramação/Diogo MoraesEstratégia Nacional de Ciência, Tecnologia e Inovação 2012 - 2015, Balanço das Atividades Estruturantes do MCTI 2011. Brasília - DF, 2012.

BRASIL, Ministério da Educação e do Desporto. Secretaria de Educação Fundamental. PCN Parâmetros Curriculares Nacionais: Ciências Naturais/Secretaria de Educação Fundamental. Brasília: MEC/SEF, 1997.

BRASIL. Secretaria de Educação Fundamental. Parâmetros curriculares nacionais: Ciências Naturais/Secretaria de Educação Fundamental. Brasília: MEC/SEF, 1998. 138p.

CITELLI, Adilson (Comunicação \& Educação), Inflexões educomunicativas Ano XVII, N. 1 jan/jun 2012.

COSTA Jeremias Ferreira; RENGEL, Eduardo Sérgio; GIOPPO Christiane, (II Congresso Internacional TIC e Educação) O Celular e o Ensino de Ondas na Escola: Uma Proposta Preliminar, Universidade Federal do Paraná.

CRUZ, Carlos Henrique de Brito, Academia Brasileira de Ciências (ABC), Simpósio sobre Excelência em Educação Impacto social, econômico e intelectual da ciência brasileira 21/02/2014. Carlos Henrique de Brito Cruz Acadêmico e diretor-científico da Fapesp http://www.abc.org.br/article.php3?id_article=3123. Acessado em 20/10/2014.

FERNANDES Elisângela, (REVISTA NOVA ESCOLA), David Ausubel e a aprendizagem significativa http://revistaescola.abril.com.br/formacao/david-ausubel-aprendizagem-significativa662262.shtml acessado em 20/09/2014, às 15:33hs. 
FONSECA, Ana Graciela M. F. da (Revista Eletrônica do Programa de Pós-Graduação em Mídia e Cotidiano), Aprendizagem, Mobilidade e Convergência: Mobile Learning com Celulares e Smartphones, Artigos Seção Livre, Número 2. 163-181 Junho 2013.

FREIRE, P. PEDAGOGIA DO OPRIMIDO. 17 eds. Rio de Janeiro: Editora: Paz e Terra, 1987.

FREIRE, Paulo. Pedagogia da autonomia: saberes necessários à prática educativa. São Paulo: Paz e Terra, 2011.

GOOGLE. PLAY play.google.com/store/apps/details?id=com.fitnesskeeper.runkeeper.pro\&hl=pt_BR acessado no dia 24/09/2014, às 23:56hs.

http://unesdoc.unesco.org/images/0021/002196/219641E.pdf acessado em 25/09/2014 às 03:45.

IBOPE, http://www.ibope.com.br/pt-br/noticias/paginas/52-milhoes-de-pessoas-tem-acesso-a-webpelo-celular-aponta-ibope-media.aspx 09/05/2013 acessado em 15/09/2014 às 17:36hs.

MANNING, Peter K. Metaphorsof the fied: Varieties of organizational discourse, In Administrative Science Quarterly, vol. 24, no 4, December 1979, p. 660-671.

MARCOLIN, Neldson I Edição 221 - Julho de 2014, http://revistapesquisa.fapesp.br/2014/07/15/cientista-e-documentarista/acessado acessado em 20/10/2014.

MORAN, José Manuel; MASETTO, Marcos T.; BEHRENS, Marilda Aparecida. Novas tecnologias e mediação pedagógica. Campinas: Papirus, 2000.

MOREIRA, Marco A. Mapas Conceituais e Diagramas V. Instituto de Física, UFRGS, 2006. http://www.if.ufrgs.br/ moreira/Livro_Mapas_conceituais_e_Diagramas_V_COMPLETO.pdf

MOREIRA, Marco Antônio. Aprendizagem significativa. Brasília: Ed. da UnB, 1998.

MOURÃO, Ronaldo Rogério de Freitas. Explicando a Teoria da Relatividade. Editora Ediouro, 2005.

NÓVOA, Antônio. (Revista Nova Escola). Professor se forma na escola. Edição 142, MAIO 2001.

PACIEVICHT, Thais. (INFOESCOLA), http://www.infoescola.com/curiosidades/historia-do-telefone/ acessado em 15/09/2014 às 17:22hs.

PROVIR o futuro se aprende http://porvir.org/porfazer/10-dicas-13-motivos-para-usar-celular-naaula/20130225 acessado em 25/09/2014, às 21:26hs.

RITCHIE, Patricio Henríquez, (Revista Electrónica "Actualidades Investigativas en Educación"), Nuevos Procesos de Interactividad e Interacción Social: Uso de Smartphones por Estudiantes y Docentes Universitarios, Volumen 13, Número 3, Año 2013, ISSN 1409-4703.

RUIZ, Paulina A. Novas tecnologias e estudantes chilenos do Ensino Secundário. Contribuições para a discussão sobre a existência de novos aprendizados. Pontificia Universidad Católica de Chile, Facultad de Educación, Estudios Pedagógicos XXXIX, № 2: 279-298, 2013. 
UNESCO - Organização das Nações Unidas para a Educação, a Ciência e a Cultura - Orientações de Política para a Aprendizagem Móvel. 7, place de Fontenoy, 75352 Paris 07 SP, França 2013. Ensino de Ciências e Desenvolvimento: o que pensam os cientistas / organizado por Jorge Werthein e Célio da Cunha. -- 2.ed. -- Brasília: UNESCO, Instituto Sangari, 2009.276 p.

VIEIRA, Leonardo Pereira. Experimentos de Física com Tablets e Smartphones. Rio de Janeiro, 2013.

WISMAN, R. F.; FORINASH, K. Science in your pocket. International Journal on Handson Science, v. 1, n. 1, p. 1-9, set. 2008. 